https://doi.org/10.52240/1857-2367.2020.2(21).10

CZU: $582.28: 630 * 44(478)$

\title{
MACROMICOBIOTA BASARABIEI
}

\author{
Ștefan MANIC \\ Grădina Botanică Națională (Institut) „,Al. Ciubotaru”, \\ Chişinău, Republica Moldova
}

\begin{abstract}
Rezumat: Cercetările vizând diversitatea taxonomică a macromicetelor, pe parcursul a mai bine de trei deceni (1976-2019), au scos în evidență 836 de taxoni în micobiota Republicii Moldova, care aparţin la 227 genuri, 81 familii, 26 ordine, 8 clase, încadrate în 3 filumuri din 2 regnuri Fungi şi Protozoa. Conform modului de hrană, toate speciile sunt repartizate în trei grupuri trofice: simbiotrofe, saprotrofe şi saproparazite. Spectrul macromicetelor din formațiunile forestiere investigate reflectă o superioritate numerică a taxonilor din pădurile cu stejar pedunculat. Studiul însemnătăţii practice a macromicobiotei inventariate a scos în evideță 121 specii comestibile și 57 specii toxice.
\end{abstract}

Cuvinte-cheie: Macromicobiota, taxoni, simbiotrof, saprotrof, formațiuni forestiere, saproparazit, comestibil, toxic.

\section{MACROMYCOBIOTA IN BESSARABIA}

\author{
Ștefan MANIC \\ “Al. Ciubotaru” National Botanical Garden (Institute), \\ Chisinau, Republic of Moldova
}

\begin{abstract}
The research on the taxonomic diversity of macromycetes, conducted for over three decades (1976-2019) has revealed 836 taxa, in the mycobiota of the Republic of Moldova, which belong to 227 genera, 81 families, 26 orders, 8 classes, included in 3 phyla from 2 kingdoms - Fungi and Protozoa. According to the mode of nutrition, all species are classified into three trophic groups: symbiotrophic, saprotrophic and saproparasitic. The spectrum of macromycetes from the investigated forest areas has revealed a numerical superiority of taxa in pedunculate oak forests. The study on the practical significance of the inventoried macromycobiota has indicated 121 edible species and 57 toxic species.
\end{abstract}

Key words: macromycobiota, taxa, symbiotroph, saprotroph, forest areas, saproparasite, edible, toxic.

Studierea diversităţii biologice a lumii vii reprezintă mereu una din importantele priorităţi ştiinţifice de cercetare în domeniul cunoaşterii legităţilor funcţionării ecosistemelor naturale. În acest context, contribuţia macromicetelor la menţinerea durabilităţii şi stabilităţii asociaţiilor naturale este semnificativă. Ele reprezintă veriga de bază, cea mai importantă parte a blocului heterotrof al ecosistemelor în care are loc procesul de descompunere şi returnare a substanţelor organice în ciclul natural biogeochimic.

Având în vedere importanța deosebită a ciupercilor în procesul funcționării biogeocenozelor, problemele de inventariere a micobiotei şi de identificare a legităţilor repartizării geografice a speciilor sunt importante sarcini ale micologiei.

Timp îndelungat, cercetarea macromicetelor din Basarabia a rămas în afara atenţiei specialiştilor. Informaţii despre unii reprezentanţi ai macromicetelor se semnalau, de obicei, paralel cu studierea altor grupuri sistematice de ciuperci. Astfel, Sredinschi N. K. [27], studiind flora şi vegetaţia regiunii Novorosiisk şi a Basarabiei, aduce date despre inventarierea a patru specii: Agaricus campestris L., Coprinus atramentarius (Bull.) Redhead, 
Vilgalys \& Moncalvo, Flammulina velutipes (Curtis) Singer, Psathyrella candolleana (Fr.) Maire. De rând cu cercetarea ciupercilor microscopice patogene pe teritoriul Basarabiei, Dekenbah C. N. [19] indică şi o specie de macromicete - Armillariella mellea (Vahl) P. Kumm. Mai târziu, Andreev V. N. (1949), în lucrarea dedicată plantelor toxice din Moldova, indică patru specii de macromicete - Amanita muscaria (L.) Lam., A. phalloides (Vaill. ex Fr.) Link, Boletus satanas Lenz, Hypholoma fasciculare (Huds.) P. Kumm. În cadrul cercetărilor ciupercilor fitopatogene ale pomilor fructiferi, Popuşoi I.S. [24] indică şi 2 specii de macromicete - Polyporus arcularius (Batsch) Fr. şi P. brumalis (Pers.) Fr., iar Nicolaeva M.G. [23], în lucrarea de licenţă, indică 47 de specii inventariate din ocolul silvic Lozova, însă au fost publicate numai 12 specii: Lactarius flexuosus (Pers.) Gray, $L$. zonarius (Bull.) Fr., L. piperatus (L.) Pers., Leccinum pseudoscabrum (Kallenb.) Śutara, Polyporus squamosus (Huds.) Fr., Russula adusta (Pers.) Fr., R. aeruginea Lindblad ex Fr., $R$. azurea Bres., $R$. delica Fr., $R$. foetens Pers., $R$. rosea Pers., $R$. vesca Fr. Cercetând componenţa specifică a ciupercilor de pe fructele nucului comun, Prostacova F.G. [25] indică şi o specie de macromicete - Marasmius rotula (Scop.) Fr.

Cercetările sistematice ale macromicetelor (ord. Agaricales, Boletales, Russulales şi Polyporales) au fost iniţiate în anul 1976, în cadrul Grădinii Botanice a Academiei de Ştiinţe a Moldovei, ca tematică de cercetare a Laboratorului de Floră şi Geobotanică. În baza acestor cercetări, pe lângă cele 23 specii de macromicete deja cunoscute, au fost inventariate şi publicate 251 specii noi pentru micobiota Republicii Moldova [20, 21].

Cercetările sistematice au fost continuate în perioada anilor 1980-1990, în acelaşi laborator, în cadrul tematicii de stat „Inventarierea florei şi vegetaţiei Rezervaţiei „Plaiul Fagului”. În urma cercetărilor, în anul 1987 a fost publicat un inventar de 241 de specii identificate din această rezervaţie [22]. În anul 2003, Obuh şi al. [13,15] publică lucrarea „Diversitatea şi răspândirea Afiloforalelor (ord. Aphylophorales) în Rezervaţia „Plaiul Fagului" şi pădurile adiacente", în care se prezintă un inventar de 68 de specii.

Începând cu anul 1990 şi până în prezent, cercetările au fost extinse asupra tuturor macromicetelor din toate grupurile taxonomice ale regnurilor Protozoa şi Fungi. Extinderea cercetării macromicetelor a fost posibilă graţie colaborării cu specialiştii din Rusia (Бурова Л., Коваленко А., Нездойминого Э.), România (M. Toma, G. Negrean, T. Chifu, C. Tănase, M. Pîrvu, A. Pop ) şi cu grupul de micologi din Sainte-Segolène din Franţa (P. Roux, P. Chapon, V. Dumas). Ca rezultat al acestei colaborări, au fost publicate mai multe lucrări de valoare $[1,6,7,9,10,12,14,26]$.

Cercetările micologice efectuate pe teritoriul Republicii Moldova, în perioada 19762018, au permis inventarierea a 836 taxoni de macromicete [5, 29] (Tabelul 1).

Macromicobiota inventariată, din punct de vedere sistematic, aparţine la 227 genuri, 81 familii, 26 ordine, 8 clase, încadrate în 3 încrengături din cadrul a 2 regnuri: Fungi şi Protozoa.

Încrengătura MYCETOZOA este reprezentată prin 16 specii, ce aparţin la 10 genuri, încadrate în 8 familii, 4 ordine din clasa Myxogastria. Cel mai reprezentativ ordin din clasa Myxogastria este ordinul Trichiales, cu 6 specii, urmat de ordinul Physarales, cu 5 specii. La polul opus se găsesc ordinele Liciales și Protosteliales, respectiv cu 3 și 2 specii. Majoritatea genurilor sunt reprezentate doar printr-o specie, excepţie fac genurile Fuligo și Arcyria cu câte 3 specii. 
Tabelul 1. Ponderea numerică a categoriilor taxonomice de macromicete

\begin{tabular}{|c|c|c|c|c|c|}
\hline Încrengătura & Clasa & Ordinul & Nr. fam & Nr. gen. & Nr. spec. \\
\hline \multirow{4}{*}{ Mycetozoa } & \multirow{4}{*}{ Myxogastria } & Liceales & 1 & 3 & 3 \\
\hline & & Physarales & 3 & 3 & 5 \\
\hline & & Protosteliales & 1 & 1 & 2 \\
\hline & & Trichiales & 2 & 3 & 6 \\
\hline \multirow{5}{*}{ Ascomycota } & \multirow[b]{2}{*}{ Leotiomycetes } & Helotiales & 2 & 4 & 5 \\
\hline & & Leotiales & 2 & 2 & 2 \\
\hline & Pezizomycetes & Pezizales & 8 & 19 & 38 \\
\hline & \multirow{2}{*}{ Sordariomycetes } & Hypocreales & 2 & 2 & 3 \\
\hline & & Xylariales & 1 & 3 & 7 \\
\hline \multirow{17}{*}{ Basidiomycota } & \multirow{14}{*}{ Agaricomycetes } & Agaricales & 24 & 105 & 475 \\
\hline & & Auriculariales & 1 & 2 & 5 \\
\hline & & Boletales & 7 & 14 & 54 \\
\hline & & Cantharellales & 3 & 4 & 6 \\
\hline & & Corticiales & 1 & 2 & 3 \\
\hline & & Geastrales & 1 & 1 & 5 \\
\hline & & Gloeophyllales & 1 & 1 & 1 \\
\hline & & Gomphales & 2 & 3 & 6 \\
\hline & & Hymenochaetales & 2 & 11 & 19 \\
\hline & & Phallales & 1 & 2 & 3 \\
\hline & & Polyporales & 6 & 29 & 49 \\
\hline & & Russulales & 5 & 9 & 132 \\
\hline & & Sebacinales & 1 & 1 & 2 \\
\hline & & Thelephorales & 1 & 1 & 2 \\
\hline & Atractielomyces & Atractiellales & 1 & 1 & 1 \\
\hline & Dacrymycetes & Dacrymycetales & 1 & 1 & 1 \\
\hline & Tremellomycetes & Tremellales & 1 & 1 & 1 \\
\hline 3 & 8 & 26 & 81 & 227 & 836 \\
\hline
\end{tabular}

Încrengătura ASCOMYCOTA este reprezentată de 55 specii de macromicete, ce aparţin la 29 genuri, încadrate în 15 familii, 5 ordine şi 3 clase. Cel mai reprezentativ din această încrengătura este ordinul Pezizales, cu 38 specii din 18 genuri, ce aparțin la 8 familii, urmat de ordinul Xylariales, cu 7 specii şi 3 genuri din familia Xylariaceae, care, după numărul de specii, este și cea mai reprezentativă din încrengătura ASCOMYCOTA [7, 8].

Încrengătura BAZIDIOMYCOTA este cea mai reprezentativă din macromicobiota teritoriului cercetat şi cuprinde 765 specii din 188 de genuri, 58 de familii, 17 ordine și 4 clase. Cel mai reprezentativ ordin din Încrengătura BAZIDIOMYCOTA este ordinul Agaricales, cu 475 specii, urmat de ordinul Russulales, cu 133 specii și Boletales cu 54 specii. Cele mai reprezentative familii din acest ordin sunt familiile Russulaceae, cu 117 specii, Agaricaceae cu 63, urmată de Tricholomataceae cu 63 și Cortinariaceae, cu 49 specii. O diversitate ridicată din această încrengătură se regăsește în genurile Russula, cu 79 de specii, Cortinarius, cu 47 de specii, Lactarius, cu 39 de specii, Boletus și Mycena, cu câte 23 de specii.

În primele 10 familii se regăsesc 491 de specii sau mai bine de jumătate $(58,7 \%)$ 
din numărul total de specii inventariate de pe teritoriul luat în studiu. Cu părere de rău, nu putem să comparăm în detalii macromicobiota cercetată de noi cu cele din teritoriile limitrofe (Ucraina și România), deoarece aceste regiuni se deosebesc mult atât după suprafaţă, cât şi după condiţiile fitogeografice şi climaterice. Totuşi, chiar dacă vom compara în general macromicobiota acestor țări, se va vedea că poziţia dominantă a familiilor Tricholomataceae, Russulaceae şi Cortinariaceae, stabilită pentru macromicobiota regiunii, se menţine şi în macromicobiota întregii regiuni Holarctice. [28]

După primele locuri pe care le ocupă familiile Agaricaceae, Boletaceae şi Pluteaceae, ai căror reprezentanți sunt răspândiți pe larg în pădurile de foioase, se poate concluziona că macromicobiota din Moldova poartă caracter nemoral.

Ciupercile sunt foarte exigente faţă de condiţiile ecologice (temperatură, umiditate, substrat, vegetaţie, tipul de sol, lumină ş a.). Dintre toţi factorii ecologici pentru ciuperci, ca organisme heterotrofe, foarte important este substratul nutritiv (Figura 1).

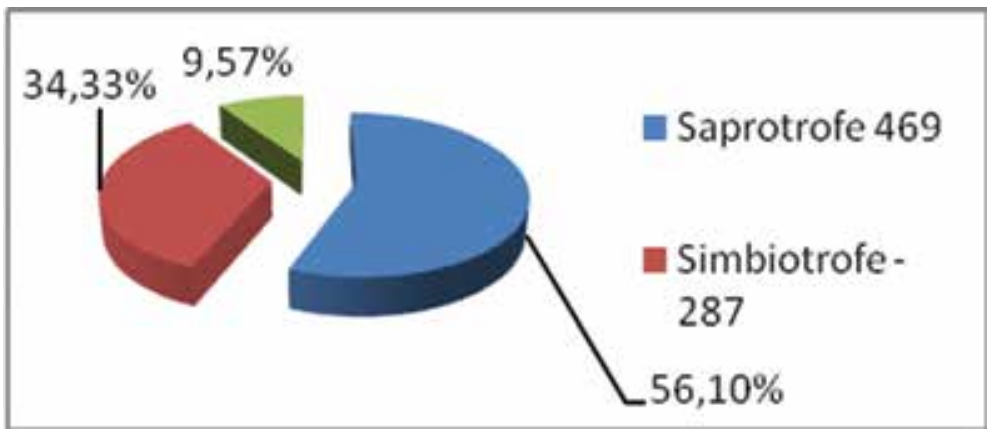

Figura 1. Ponderea numerică și procentuală a speciilor în grupurile ecotrofice

În timpul cercetării macromicetelor din Moldova, o atenţie deosebită a fost acordată relațiilor ciupercilor cu substratul şi participarea lor la descompunerea lui $[4$, 11]. De aici rezultă că toate speciile de ciuperci care alcătuiesc micobiota regională, după modul de hrană, se divizează în trei grupuri trofice: simbiotrofe, saprotrofe și saproparazite.

Macromicetele saprotrofe au cea mai mare diversitate, fiind prezente în teritoriu prin 469 de taxoni, care reprezintă $56,10 \%$ din totalul speciilor identificate [11]. Macromicetele saprotrofe, în funcție de substratul pe care se dezvoltă miceliul, se divizează în 6 subgrupuri: lignicole, humicole, foliicole, coprofile, carbofile și carpofile. Ponderea subgrupurilor trofice de macromicete este diferită; preponderente s-au dovedit a fi cele humicole $(47,33 \%)$ și lignicole (43,07 \%), o prezenţă considerabilă au şi cele foliicole $(8,74 \%)$. Celelalte grupuri deţin un procent relativ redus - sub 5\%.

Macromicetele simbiotrofe din teritoriul cercetat formează un grup destul de numeros - 287 specii. Pentru ele sunt caracteristice legăturile simbiotice cu diverşi arbori şi arbuşti. Necesitatea legăturilor simbiotice ale ciupercilor nu este la fel, după cum nu este la fel nici cea a arborilor $[16,17]$. Sunt specii de ciuperci care formează legături simbiotice atât cu arborii de foioase, cât şi cu cei de conifere. Astfel de specii inventariate în teritoriul luat în studiu sunt: Amanita pantherina, A. vaginata, Lactarius vellereus, Russula delica, $R$. foetens, $R$. nigricans.

O altă categorie de ciuperci micorizante au relații simbiotice numai cu anumite specii de foioase sau conifere sau chiar numai cu una dintre acestea. În fitocenozele pădurilor din Moldova, în afară de stejar, destul de frecvent se întâlnesc specii ca: Amanita 
solitaria, Boletus aereus, B. impolitus, B. edulis, Lactarius quietus, Hygrophorus mesotephrus, Russula sororia, $R$. verescens; cu fagul: Lactarius blennius, L. subdulcis, $R$. fellea, $R$. illota, $R$. romellii, cu carpenul: Leccinum griseum; cu mesteacănul: Lactarius pubescens, Russula aeruginea, Leccinum scabrum; cu plopul: Leccinum duriusculum, $L$. albostipitatum, L. aurantiacum.

În macromicobiota cercetată ciupercile saproparazite sunt reprezentate prin 80 de specii, care îşi procură elementele necesare supravieţuirii din celulele țesuturilor vii, iar ,odată cu moartea arborelui, trec la modul de hrană saprotrof. Majoritatea absolută a ciupercilor lignicole inventariate pe arborii vii au fost semnalate și pe trunchiurile moarte $[2,3,4]$. Din aceste considerente, cu o doză de convingere destul de înaltă, putem să afirmăm că printre speciile de macromicete inventariate, ciuperci parazite obligatoriu nu se întâlnesc pe teritoriul luat în studiu.

Apariția corpurilor sporifere ale macromicetelor pe teritoriul Republicii Moldova practic se extinde pe tot parcursul anului, dar masa de bază a ciupercilor apare din aprilie până în noiembrie. Observaţii asupra fenofazelor de formare a corpurilor sporifere s-au dus pe parcursul întregii perioade de cercetare (1977-2019). Pentru fiecare specie inventariată pe teritoriul Moldovei, au fost efectuate în fiecare an observații asupra a trei etape fenofazice: apariția corpurilor sporifere; fixarea apogeului de formare și sfîrșitul apariției lor.

Analiza datelor multianuale obținute a permis stabilirea începutului fenofazelor de formare a corpurilor sporifere, cu evidențierea a 4 perioade sezoniere: vernală (aprilie-mai); estivală (iunie-iulie); autumnală (septembrie-octombrie) și multisezoniere (primavara-vara; vara-toamna; primăvara-vara-toamna). În baza acestor date, pentru ciupercile comestibile și cele toxice, a fost întocmit calendarul formării corpurilor sporifere.

Repartizarea spaţială a speciilor de macromicete în diverse tipuri de habitate nu este aleatorie. Aflarea lor în diverse nişe ecologice este determinată de tipul lor de hrană (saprotrof, simbiotrof și saproparazit), în strânsă legătură cu anumiți factori ecologici și cenologici. Din cele 836 specii inventariate pe teritoriul cercetat, $796(95,2 \%)$ specii habitează în vegetația forestieră și mai puțin de 5\% - pe terenuri neîmpădurite (vegetație de pajiști și vegetaţie sinantropă) (Figura 2).

Cercetările noastre asupra distribuției macromicetelor în vegetația forestieră au scos în evidență pentru fiecare formațiune silvică componența taxonomică a macro-

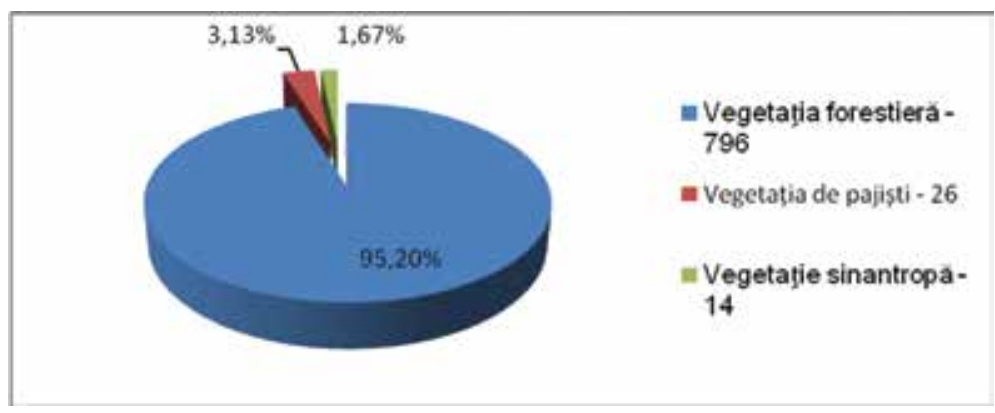

Figura 2. Distribuţia numerică și procentuală a macromicetelor pe tipuri de vegetație micetelor și repartizarea lor în diverse habitate din aceste formațiuni. Spectrul macromicetelor din formațiunile forestiere investigate reflectă o superioritate numerică a taxonilor din pădurile cu stejar pedunculat (712 specii), urmată de cele 
din gorunete (613 sp.) și cele din făgete ( 579 sp.). Pădurile cu stejar pufos sunt aproape de trei ori mai sărace după numărul de taxoni (240 specii) decât celelalte formațiuni forestiere (Figura 3).

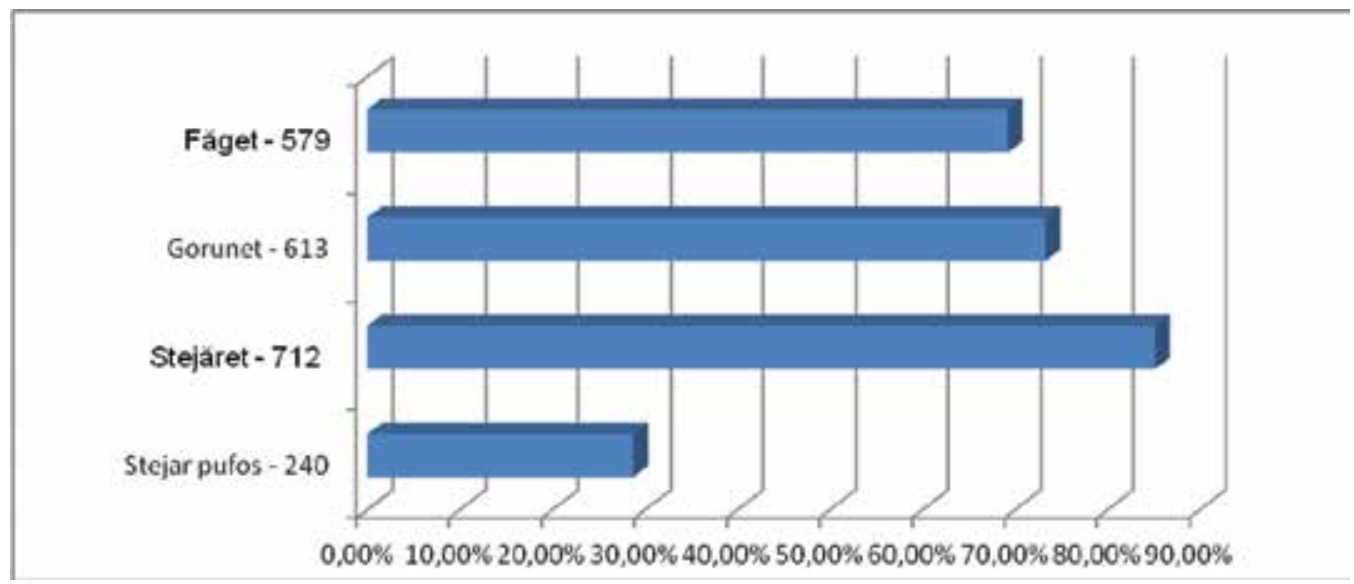

Figura 3. Ponderea numerică și procentuală a macromicobiotei pe formațiuni forestiere

Majoritatea speciilor identificate sunt răspândite în zona centrală a republicii (795 specii), concentrate în vegetaţia forestieră. În nordul teritoriului, au fost inventariate 468 specii, iar în partea de sud s-au înregistrat 398 specii.

În baza cercetărilor efectuate pe teritoriul Basarabiei și consultării literaturii de specialitate, au fost obținute următoarele date: 121 specii de macromicete pot fi folosite în alimentaţie $[10,11]$, ceea ce reprezintă $14,5 \%$ din totalul speciilor identificate în teritoriul cercetat; 57 specii sunt toxice, ceea ce reprezintă $6,8 \% ; 658$ specii pot fi definite ca necomestibile, ceea ce reprezintă $78,7 \%[2,3]$. Circa 30 de specii comestibile corespund cerinţelor de bază ale standardelor de stat pentru colectare, însă, după indicii cantitativi, nu prezintă interes industrial.

\section{BIBLIOGRAFIE}

1. Begu A. şi al. Lumea vegetală a Moldovei. Vol.1. Ciuperci. Plante fără flori. Chişinău, Ştiinţa, 2007, 200 p.

2. Bon M. Champignons de France et d'Europe occidentale. Paris, Arthaud, 1988, 368 p.

3. Courtecuisse R. Champignons d'Europe. Paris, Delachaux et Niestlé Lausanne, 2000, 465 p.

4. Jülich W. Guida alla deteminazione dei funghi. Aphyllophorales, Heterobasidiomycetes, Gastromycetes. Saturnia, 1989. $553 \mathrm{~s}$.

5. Kirk P. et all. Dictionary of the fungi. 10 th Edition. CABI Bioscience, UK, 2008. 784 p.

6. Manic Ş. și al. Cercetări asupra macromicetelor din rezervaţia „Codrii”. În: Tezele rapoartelor simpozionului jubiliar „Rezervaţia „Codrii”-25 de ani. Realizări, probleme, perspective”. Lozova, 1996, p. 199-201.

7. Manic Ş. și al. Rezervaţia "Codrii “ diversitatea biologică. Chișinău, Ştiinţa, 2006, 92 p.

8. Manic Ş., Manic T. Contribution to the truffles researches in Republic of Moldova: In: XV Congress of European Mycologists, Saint Petersburg, Russia, September 16-21, 2007, p. 133-134.

9. Manic Ș. și al. Conspectul diversității biologice a Rezervației “Codrii”. Chișinău, Știința, 2011, $328 \mathrm{p}$. 
10. Manic Ș. Ghid de ciuperci din Republica Moldova. Chișinău. Tipografia centrală, 2018, 448 p.

11. Moser M. Guida alla determination dei funghi. Polyporales, Boletales, Agaricales, Russulales). 3, Trento: Saturnia, 1993, 565 p.

12. Negrean G., Manic Ş. Micromicete din rezervaţia „Codrii” În: Materialele Conferinţei ştiinţifice a Botaniştilor, "Ocrotirea, reproducerea şi utilizarea plantelor”. Chişinău, 1994, p. 186-187.

13. Obuh P. și al. Diversitatea și răspândirea Afiloforalelor (ord, Aphylophorales) în rezervația "Plaiul fagului” și pădurile adiacente. În: Dezvoltarea durabilă a sectorului forestier al Republicii Moldova. Materialele conferinței științifice internaționale. Chişinău, 2003, p. 250-257.

14. Sălăgeanu Gh., Sălăgeanu A. Determinator pentru recunoaşterea ciupercilor comestibile.

15. Ungureanu I., Rayss T., Obuh P. Contribuții la cunoașterea florei ciupercilor din pădurile Moldovei. În: Bilanțul activității științifice a USM în anii 2000-2002. Tezele conf. corpului didactico-științific. Chișinău, 2003, p. 213-214

16. Romagnesi H. Les Russules d'Europe et d'Afrique du Nord. Paris: Bordas, 1967, 998 p.

17. Roux P. Mille Et Un Champinions. France: Roux-Sainte Sigolène, 2006, 876 p.

18. Андреев В. Н. Ядовитые растения Молдавской ССР.- Кишинев: Госиздат Молдавии, 1949. - 80с.

19. Декенбах К. Н. Грибы Бесарабии. В: Бот. записи СПб университета, XY, 1899, 1-57 с.

20. Маник С. И. Видовой состав агариковых грибов Центральной части Молдавии. В: Известия АН. МССР. 1978. Серия биол. и химич. Наук. № 3, с. 45-51

21. Маник С. И. Новые для микофлоры СССР виды агариковых грибов Молдавии. В: Изв. АН МССР. 1981. Серия биол. и химич. наук. № 2, с. 82- 83.

22. Маник С. И. Шляпочные грибы Реденского леса Молдавии. В: Рукопись деп. в ВИНИТИ. 2843-B87, 1987, $12 \mathrm{c.}$

23. Николаева М. Г. Шляпочные грибы Лозовского лесничества. В: Труды III научн. конф. молодых ученых Молдавии. Кишинев: Штиинца, 1964, с. 17-18.

24. Попушой И. С. Плодовые гнили монилиальный ожог плодовых деревьев.Кишинев: Картеа Молдовенеаскэ, 1963, 26 с.

25. Простакова Ф. Г. Видовой состав грибов на плодах грецкого ореха. В сб.: Грибы на культурных растениях Молдавии. Кишинев: Штиинца, 1976, с. 14-24.

26. Симонов Г., Маник С. Лесные растения. Грибы - макромицеты, лишайники, мохообразные. Кишинев, Штиинца, 1987, 198с.

27. Срединский Н. К. Материалы для флоры Новороссийского края и Бессарабии. Одесса, 18721873,2 , с. $73-129$.

28. Толмачев А. И. Введение в географию растений.Л.: Ленингр. ун-т, 1974. 243 с.

29. www.indexfungorum.org (vizitat, 9.10. 2020). 